\title{
BMJ Open Association between blood pressure levels and cardiovascular deaths: a 20- year follow-up study in rural China
}

Mengying Wang (D) , ${ }^{1}$ Tao Wu, ${ }^{1}$ Canqing Yu, ${ }^{1}$ Wenjing Gao, ${ }^{1}$ Jun Lv (D) , ${ }^{1}$ Yiqun Wu, ${ }^{1}$ Xueying Qin, ${ }^{1}$ Xun Tang (D) , ${ }^{1}$ Pei Gao, ${ }^{1}$ Siyan Zhan (D) , ${ }^{1}$ Weihua Cao, ${ }^{1}$ Qingshui Zhao, ${ }^{2}$ Shaoping Huang, ${ }^{2}$ Dongli Yang, ${ }^{2}$ Liming Li, ${ }^{1}$ Yonghua Hu${ }^{1}$

To cite: Wang M, Wu T, Yu C, et al. Association between blood pressure levels and cardiovascular deaths: a 20-year follow-up study in rural China. BMJ Open 2020;10:e035190. doi:10.1136/ bmjopen-2019-035190

- Prepublication history and additional material for this paper are available online. To view these files, please visit the journal online (http://dx.doi. org/10.1136/bmjopen-2019035190).

Received 22 0ctober 2019 Revised 20 January 2020 Accepted 04 February 2020

Check for updates

(C) Author(s) (or their employer(s)) 2020. Re-use permitted under CC BY-NC. No commercial re-use. See rights and permissions. Published by BMJ.

${ }^{1}$ Epidemiology and Biostatistics, Peking University, Beijing, China ${ }^{2}$ General Office, Fangshan District Health Commission, Beijing, China

Correspondence to

Dr Tao Wu; twu@bjmu.edu.cn

\section{ABSTRACT}

Objectives The 2017 American College of Cardiology/

American Heart Association (ACC/AHA) hypertension guideline recommended $130 / 80 \mathrm{~mm} \mathrm{Hg}$ as blood pressure (BP) target goals. However, the generalisability of this recommendation to populations at large with hypertension remains controversial. We assessed the association between BP and cardiovascular diseases (CVDs) mortality using a 20-year follow-up study among Chinese populations.

Design Prospective cohort study.

Participants 7314 participants were followed up for a median of 20 years in Fangshan District, Beijing, China. Methods The primary outcome variable was death from cardiovascular causes. The adjusted HR for CVDs mortality associated with baseline BP was calculated using Cox regression analysis.

Results We identified 350 deaths from CVDs (148 stroke, 113 coronary heart disease and 89 other CVDs) during follow-up. Hypertension (defined by systolic BP (SBP)/ diastolic BP (DBP) $\geq 140 / 90 \mathrm{~mm} \mathrm{Hg}$ ) was significantly associated with mortality due to CVDs ( $\mathrm{HR}=2.49,95 \%$ $\mathrm{Cl}=1.77$ to 3.50 ) among people aged $35-59$ years rather than people aged $\geq 60$ years. In addition, there was no significant association between stage 1 hypertension defined by the 2017 ACC/AHA (SBP/DBP of 130-139/80$89 \mathrm{~mm} \mathrm{Hg}$ ) and CVDs mortality when compared with SBP/ DBP of $<120 / 80$ in neither the participants aged $<60$ years ( $\mathrm{HR}=0.90,95 \% \mathrm{Cl}=0.54$ to 1.50 ) nor participants aged $\geq 60$ years $(\mathrm{HR}=1.47,95 \% \mathrm{Cl}=0.94$ to 2.29$)$.

Conclusion The study revealed hypertension of SBP/ $\mathrm{DBP} \geq 140 / 90 \mathrm{~mm} \mathrm{Hg}$ was an important risk factor of CVDs mortality, especially among people aged $35-59$ years. However, stage 1 hypertension under the definition of 2017 ACC/AHA was not associated with an increased risk of CVDs mortality. This study indicated that whether adopting the new hypertension definition needs further consideration in rural Chinese populations.

\section{INTRODUCTION}

Hypertension is the first risk factor of cardiovascular diseases (CVDs), accounted for 7.8 million deaths and 148 million disability life years lost worldwide in 2015. ${ }^{1}$ It has been reported that hypertension affected nearly
Strengths and limitations of this study

- The prospective study had a relatively long followup time of 20 years.

- The study examined the association between high blood pressure and mortality from cardiovascular diseases (CVDs), which were hard outcomes.

- Hypertension was defined by systolic blood pressure or diastolic blood pressure at baseline while we failed to acquire blood pressure measurements during follow-up, which may underestimate the strength of the associations we observed.

Whether the effects of hypertension on CVDs mortality differ by baseline comorbidities including diabetes or chronic kidney disease was not explored due to limited data.

- The information of death was obtained from the Death Surveillance System, the participants lost to follow-up were hard to detect and may cause potential bias.

$30 \%$ of the adult population in Western countries as well as in China. ${ }^{23}$

The management of high blood pressure is a public health priority with implications for the prevention of CVDs. ${ }^{4}$ However, the optimal blood pressure, particularly for systolic blood pressure (SBP) treatment target is unclear worldwide. The 2017 American College of Cardiology/American Heart Association (ACC/AHA) Guideline for the Prevention, Detection, Evaluation, and Management of High Blood Pressure in Adults recommended 130/80 $\mathrm{mm} \mathrm{Hg}$ as blood pressure target goals. ${ }^{6}$ However, the definition of hypertension remains $\geq 140 / 90$ mm Hg in the European guideline. ${ }^{7}$

The Systolic Blood Pressure Intervention Trial (SPRINT) demonstrated intensive SBP lowering in adults without diabetes or stroke could result in significant decreases in cardiovascular events and all-cause mortality. ${ }^{8} \mathrm{~A}$ network meta-analysis conducted by Bundy et al also suggested that a more intensive 
treatment target (eg, SBP of 120-124 mm Hg) showed improvement in the prevention of CVD complications and total mortality when compared with a standard SBP target $(<140 \mathrm{~mm} \mathrm{Hg}) \cdot{ }^{9}$ However, the generalisability of SPRINT findings to populations at large with hypertension remains controversial. ${ }^{9-13}$ For example, a recent study showed that the treatment to achieve a target SBP of 110-139 $\mathrm{mm} \mathrm{Hg}$ did not result in a lower rate of death than standard reduction to a target of 140-179 $\mathrm{mm} \mathrm{Hg}$ in patients with hypertension with intracerebral haemorrhage. ${ }^{12}$

Here, we aimed to assess the relative risk of CVDs mortality associated with different stages of hypertension according to 2017 ACC/AHA using a 20-year follow-up study in China, to further evaluate the generalisability of SPRINT findings and explore the target blood pressure levels among Chinese populations.

\section{METHODS}

\section{Study design}

The participants for these analyses came from a community-based follow-up study for the prevention and treatment of hypertension, which is being conducted in Fangshan District, Beijing, China. Verbal informed consent was obtained from all participants.

\section{Inclusion and exclusion of the participants}

From January 1997 through June 1999, 8189 participants aged 35-97 years were enrolled. We excluded 669 individuals with CVDs at baseline. In addition, we dropped the participants if any of the key variables required in the analysis (blood pressure, height, weight, demographic variables or potential risk factors including smoking, alcohol consumption or high salt intake) were missing. Finally, a total of 7314 participants (3346 males and 3968 females) were included in the analysis.

\section{Outcomes variables}

The primary outcome variable was death from CVDs. The information on death was continuously obtained from the Death Surveillance System in the Center for Disease Prevention and Control in Fangshan District. The date of death was ascertained from the record in the system. We determined survival times from the date participants investigated in the baseline survey through 31 December 2017. Participants who were alive at the end of this period contributed with censored observations to the survival analyses of time to death. The causes of death were coded using the International Classification of Diseases, Ninth Revision codes from 1997 to 2001, and International Classification of Diseases, Tenth Revision codes from 2002 to 2017.

\section{Data collection}

The primary exposure variables for these analyses included age at the enrolment and the blood pressure level at baseline. Data on sociodemographic characteristics, lifestyles and medical history of the participants were collected by questionnaire interviews by trained staff members.

Participants were defined as never smokers, former smokers and current smokers. Information on alcohol consumption was obtained through asking the participants to describe their drinking status: never, light $(<$ two drinks a day) or heavy ( $\geq$ two drinks a day). Furthermore, the salt intake of the participants was assessed according to the question of what kind of taste they liked (salty taste, moderate or light taste).

Physical measurements included height, weight and blood pressure. Blood pressure levels were measured three times using a mercury sphygmomanometer by trained investigators. The mean of the three recorded measurements was included in the analysis.

Hypertension was defined as SBP $\geq 140 \mathrm{~mm} \mathrm{Hg}$, diastolic blood pressure (DBP) $\geq 90 \mathrm{~mm} \mathrm{Hg}$, self-reported antihypertensive medication in the past 2 weeks or a self -reported history of hypertension. ${ }^{3}$ In addition, according to the 2017 ACC/AHA guidelines, the participants were divided into four categories: normal blood pressure ( $\mathrm{SBP}<120 \mathrm{~mm} \mathrm{Hg}$ and $\mathrm{DBP}<80 \mathrm{~mm} \mathrm{Hg}$ ), elevated blood pressure $(120 \mathrm{~mm} \mathrm{Hg} \leq \mathrm{SBP} \leq 129 \mathrm{~mm} \mathrm{Hg}$ and $\mathrm{DBP}<80 \mathrm{~mm}$ $\mathrm{Hg}$ ), stage 1 hypertension ( $130 \mathrm{~mm} \mathrm{Hg} \leq \mathrm{SBP} \leq 139 \mathrm{~mm}$ $\mathrm{Hg}$ or $80 \leq \mathrm{DBP} \leq 89 \mathrm{~mm} \mathrm{Hg}$ ), and stage 2 hypertension ( $\mathrm{SBP} \geq 140 \mathrm{~mm} \mathrm{Hg} / \mathrm{DBP} \geq 90 \mathrm{~mm} \mathrm{Hg}$ or taking antihypertensive medications).

\section{Statistical analysis}

Student's t-test and $\chi^{2}$ tests were used to test the differences between different baseline hypertensive history groups for continuous variables and categorical variables, respectively.

Person-years for each participant were calculated as the duration from the survey date at baseline through death date or date lost to follow-up, whichever came first. The Cox proportional hazards regression model for CVDs death included baseline blood pressure level, age, sex, education level, body mass index, smoking status, alcohol use, dietary salt intake, antihypertensive medications and family history of hypertension. Participants were classified as two groups according to baseline hypertensive status, and non-hypertension $(<140 / 90 \mathrm{~mm} \mathrm{Hg})$ was treated as the reference. To test for possible interactions between age and hypertension, we categorised age with cutoffs of 60 years and hypertension as binary variables, and setting variable cross-product terms of hypertension (yes/no) with age $(<60$ and $\geq 60$ years $)$ in the model. Reference groups were $\mathrm{SBP} / \mathrm{DBP}<140 / 90 \mathrm{~mm} \mathrm{Hg}$ and age $<60$ years. We also performed a subgroup analysis according to baseline blood pressure levels (SBP/DBP: $<120 /<80$, $120-129 /<80, \quad 130-139 / 80-89, \quad 140-159 / 90-99$ and $\geq 160 / \geq 100 \mathrm{~mm} \mathrm{Hg}$ ), where SBP/DBP of $<120 /<80$ was treated as the reference group.

All analyses were performed using R software (V.3.5.1). All $p$ values for the tests were two-sided and $p$ values $<0.05$ were considered as statistically significant. 
Patient and public involvement

Patients or the public were not involved in the study.

\section{RESULTS}

Of the 7314 participants (aged $50.65 \pm 11.8$ years), the prevalence of hypertension was $30.02 \%$. According to the 2017 ACC/AHA guideline, the prevalence of hypertension was $58.96 \%$. The proportion of people aged 60 years and above was higher in patients with hypertension $(36.75 \%)$ when compared with participants without hypertension $(19.05 \%, \mathrm{p}<0.001)$. In addition, patients with hypertension were less educated than participants without hypertension $(p<0.001)$. Moreover, there were more participants with tobacco smoking $(49.27 \%$ vs $44.92 \%)$ and alcohol consumption $(31.74 \%$ vs $30.15 \%)$ among patients with hypertension when compared with participants without hypertension. Furthermore, the percentage of obesity was higher among patients with hypertension when compared with participants without hypertension $(\mathrm{p}<0.001)$ (table 1$)$.

During the median follow-up of 20 years, we have identified 609 deaths, of which 350 deaths were from CVDs (148 stroke, 113 coronary heart disease and 89 other CVDs). In the multivariable model adjusting for age, sex, educational level, smoking, alcohol consumption, dietary salt intake, body mass index (BMI), use of antihypertensive medications and family history of hypertension, we detected statistically significant association between hypertension and mortality from CVDs ( $\mathrm{HR}=1.35 ; 95 \%$ CI 1.08 to 1.69 ). In the subgroup analysis based on baseline age, we found that, for people aged 35-59 years, patients with hypertension had a higher risk of mortality from CVDs when compared with those without hypertension ( $\mathrm{HR}=2.49 ; 95 \%$ CI 1.77 to 3.50) (table 2). However, there was no significant association between hypertension and mortality due to CVDs among people aged 60 years and over $(p>0.05)$ (table 2$)$. Thus, age may significantly modify the association between hypertension and mortality from CVDs ( $p$ for interaction $<0.001$ ). We also assessed the association between hypertension and allcause, coronary heart disease and stroke mortality (online supplementary table 1).

Stratified analysis according to different baseline blood pressure showed that patients with hypertension with SBP/DBP of 140-159/90-99 and $\geq 160 / 100 \mathrm{~mm} \mathrm{Hg}$ were more likely to die of CVDs (HR=1.44; 95\% CI 1.02 to 2.03; $\mathrm{HR}=1.74 ; 95 \%$ CI 1.22 to 2.48 ) when compared with participants with SBP/DBP of $<120 / 80 \mathrm{~mm} \mathrm{Hg}$. However, we failed to detect significant associations between SBP/ DBP of $130-139 / 80-89 \mathrm{~mm} \mathrm{Hg}(\mathrm{HR}=1.18$; 95\% CI 0.85 to $1.64, \mathrm{p}=0.32)$ and $120-129 /<80 \mathrm{~mm} \mathrm{Hg}(\mathrm{HR}=1.38$; $95 \%$ CI 0.93 to $2.05, \mathrm{p}=0.11$ ) and mortality from CVDs, respectively. Furthermore, among participants aged $<60$ years at baseline, a similar trend was observed between hypertension and mortality due to CVDs, where HR was $2.32(\mathrm{p}<0.001)$ for SBP/DBP of 140-159/90-99 mm Hg and $3.25(\mathrm{p}<0.001)$ for $\geq 160 / 100 \mathrm{~mm} \mathrm{Hg}$, respectively.
Table 1 Characteristics of the participants by hypertensive status at baseline

\begin{tabular}{|c|c|c|c|}
\hline & $\begin{array}{l}\text { Patients with } \\
\text { hypertension } \\
(n=2196)\end{array}$ & $\begin{array}{l}\text { Participants } \\
\text { without } \\
\text { hypertension } \\
(n=5118)\end{array}$ & $P$ value \\
\hline \multicolumn{3}{|l|}{ Age (years), n (\%) } & $<0.001$ \\
\hline$<60$ & $1389(63.25)$ & $4143(80.95)$ & \\
\hline$\geq 60$ & 807 (36.75) & 975 (19.05) & \\
\hline \multicolumn{3}{|l|}{ Sex, n (\%) } & $<0.001$ \\
\hline Male & $1002(45.63)$ & $2344(45.80)$ & \\
\hline Female & $1194(54.37)$ & $2774(54.20)$ & \\
\hline \multicolumn{3}{|l|}{ Education, n (\%) } & $<0.001$ \\
\hline Illiterate & 805 (36.65) & $1224(23.91)$ & \\
\hline Primary & $666(30.33)$ & 1692 (33.06) & \\
\hline Middle school & $628(28.60)$ & $1917(37.46)$ & \\
\hline $\begin{array}{l}\text { High school } \\
\text { and above }\end{array}$ & $97(4.42)$ & 285 (5.57) & \\
\hline \multicolumn{3}{|c|}{ Tobacco smoking, n (\%) } & $<0.001$ \\
\hline Non-smoking & $1114(50.73)$ & 2819 (55.08) & \\
\hline Ex-smoking & $202(9.20)$ & $234(4.57)$ & \\
\hline $\begin{array}{l}\text { Current } \\
\text { smoking }\end{array}$ & $880(40.07)$ & $2065(40.35)$ & \\
\hline \multicolumn{3}{|c|}{ Alcohol consumption, n (\%) } & $<0.001$ \\
\hline Non-drinking & $1499(68.26)$ & $3575(69.85)$ & \\
\hline Ex-drinking & $510(23.22)$ & $1250(24.42)$ & \\
\hline $\begin{array}{l}\text { Current } \\
\text { drinking }\end{array}$ & $187(8.52)$ & $293(5.73)$ & \\
\hline \multicolumn{3}{|l|}{ BMI $\left(\mathrm{kg} / \mathrm{m}^{2}\right), \mathrm{n}(\%)$} & $<0.001$ \\
\hline $\mathrm{BMI}<18.5$ & $48(2.19)$ & $91(1.78)$ & \\
\hline $18.5 \leq \mathrm{BMl}<23.9$ & $956(43.53)$ & $2930(57.25)$ & \\
\hline $24.0 \leq \mathrm{BMl}<27.9$ & $811(36.93)$ & $1752(34.23)$ & \\
\hline $\mathrm{BMI} \geq 28.0$ & $381(17.35)$ & $345(6.74)$ & \\
\hline
\end{tabular}

BMI, body mass index

However, there was no significant association between hypertension and mortality from CVDs with different baseline blood pressure levels for those aged $\geq 60$ years ( $p$ for interaction $<0.001$ ) (table 3 ).

\section{DISCUSSION}

The present 20-year prospective study filled the gaps for implying the generalisability of the 2017 ACC/AHA hypertension guideline to rural Chinese populations. The results showed there was no significant association between stage 1 hypertension defined by the 2017 ACC/ AHA and CVDs mortality when compared with SBP/ DBP of $<120 / 80 \mathrm{~mm} \mathrm{Hg}$. In addition, we detected high blood pressure was associated with higher mortality from CVDs among people aged 35-59 years rather than those aged 60 years and over. The findings may contribute to the optimal management of hypertension to address the 
Table 2 MultivariableHRs of mortality from CVDs according to baseline history of hypertension

\section{CVDs mortality}

\begin{tabular}{|c|c|c|c|c|}
\hline & $\mathbf{N}$ & Deaths & $\begin{array}{l}\text { Adjusted HR } \\
(95 \% \mathrm{Cl})\end{array}$ & $P$ value \\
\hline \multicolumn{5}{|l|}{ Total } \\
\hline \multicolumn{5}{|c|}{ Baseline hypertension status } \\
\hline No & 5118 & 189 & Reference & \\
\hline Yes & 2196 & 161 & 1.35 (1.08 to 1.69$)$ & 0.01 \\
\hline \multicolumn{5}{|c|}{ Age $<60$ years } \\
\hline \multicolumn{5}{|c|}{ Baseline hypertension status } \\
\hline No & 4143 & 80 & Reference & \\
\hline Yes & 1389 & 64 & 2.49 (1.77 to 3.50$)$ & $<0.001$ \\
\hline \multicolumn{5}{|c|}{ Age $\geq 60$ years } \\
\hline \multicolumn{5}{|c|}{ Baseline hypertension status } \\
\hline No & 975 & 109 & Reference & \\
\hline Yes & 807 & 97 & $1.01(0.76$ to 1.33$)$ & 0.96 \\
\hline
\end{tabular}

CVDs, cardiovascular diseases.

growing burden of CVDs morbidity and mortality among rural Chinese populations, suggesting a large implication both to clinicians and public health practitioners.

In the current study, we first examined the association between hypertension of $\geq 140 / 90 \mathrm{~mm} \mathrm{Hg}$ and mortality from CVDs. The result showed a higher risk of mortality from CVDs in patients with hypertension when compared with participants without hypertension $(\mathrm{HR}=1.35)$, which was comparable with previous studies. ${ }^{44-16}$

Furthermore, the stratified analysis according to age groups showed that the associations between hypertension and CVDs mortality were stronger among participants aged 35-59 years than those aged 60 years and above. A previous study also showed the association was significant in the age groups of 35-44 and 45-59 years rather than in the group of $\geq 60$ years. ${ }^{12}$ Besides, a study based on pooling data from seven diverse US cohort studies showed that individuals who experienced blood pressure increases prior to middle age have associated higher remaining lifetime risk for CVDs when compared with those who had developed hypertension later in age 55 years. ${ }^{17}$ Similarly, a previous meta-analysis of 13 prospective cohort studies involving 396200 participants showed that prehypertension was not associated with CVDs risk among older populations with age $\geq 60$ years. ${ }^{18}$ It is reported that the cardiovascular risk for patients with hypertension decreased as the age of onset increased from 40 to 69 years. ${ }^{19}$ Possible explanations for the agespecific association between hypertension and mortality from CVDs needs further studies to explore. In addition, it is important to consider the influence of age in the diagnosis of hypertension.

In clinical practice, the staging of hypertension defined by SBP and DBP corresponds with the graded increased risk of cardiovascular disease and events and is in relation
Table 3 Multivariable HRs of mortality from CVDs according to baseline blood pressure levels

CVDs mortality

\begin{tabular}{|c|c|c|c|c|}
\hline & \\
\hline & $\mathbf{N}$ & Deaths & $\begin{array}{l}\text { Adjusted HR } \\
(95 \% \mathrm{Cl})\end{array}$ & $P$ value \\
\hline \multicolumn{5}{|l|}{ Total } \\
\hline$<120 / 80 \mathrm{~mm} \mathrm{Hg}$ & 2132 & 61 & Reference & \\
\hline $\begin{array}{l}120-129 /<80 \\
\mathrm{~mm} \mathrm{Hg}\end{array}$ & 920 & 43 & 1.38 (0.93 to 2.05$)$ & 0.11 \\
\hline $\begin{array}{l}130-139 / 80-89 \\
\mathrm{~mm} \mathrm{Hg}\end{array}$ & 2180 & 91 & $1.18(0.85$ to 1.64$)$ & 0.32 \\
\hline $\begin{array}{l}140-159 / 90-99 \\
\mathrm{~mm} \mathrm{Hg}\end{array}$ & 1239 & 80 & 1.44 (1.02 to 2.03$)$ & 0.04 \\
\hline $\begin{array}{l}\geq 160 / 100 \mathrm{~mm} \\
\mathrm{Hg}\end{array}$ & 843 & 75 & 1.74 (1.22 to 2.48$)$ & $<0.01$ \\
\hline \multicolumn{5}{|l|}{ Age $<60$ years } \\
\hline$<120 / 80 \mathrm{~mm} \mathrm{Hg}$ & 1813 & 32 & Reference & \\
\hline $\begin{array}{l}120-129 /<80 \\
\mathrm{~mm} \mathrm{Hg}\end{array}$ & 727 & 21 & 1.46 (0.84 to 2.55$)$ & 0.18 \\
\hline $\begin{array}{l}130-139 / 80-89 \\
\mathrm{~mm} \mathrm{Hg}\end{array}$ & 1691 & 29 & $0.90(0.54$ to 1.50$)$ & 0.70 \\
\hline $\begin{array}{l}\text { 140-159/90-99 } \\
\mathrm{mm} \mathrm{Hg}\end{array}$ & 818 & 34 & 2.31 (1.41 to 3.79$)$ & $<0.001$ \\
\hline $\begin{array}{l}\geq 160 / 100 \mathrm{~mm} \\
\mathrm{Hg}\end{array}$ & 483 & 28 & 3.25 (1.92 to 5.50$)$ & $<0.001$ \\
\hline \multicolumn{5}{|l|}{ Age $\geq 60$ years } \\
\hline$<120 / 80 \mathrm{~mm} \mathrm{Hg}$ & 319 & 29 & Reference & \\
\hline $\begin{array}{l}120-129 /<80 \\
\mathrm{~mm} \mathrm{Hg}\end{array}$ & 193 & 22 & $1.28(0.74$ to 2.24$)$ & 0.38 \\
\hline $\begin{array}{l}130-139 / 80-89 \\
\mathrm{~mm} \mathrm{Hg}\end{array}$ & 489 & 62 & 1.47 (0.94 to 2.29$)$ & 0.09 \\
\hline $\begin{array}{l}140-159 / 90-99 \\
\mathrm{~mm} \mathrm{Hg}\end{array}$ & 421 & 46 & $1.16(0.72$ to 1.85$)$ & 0.55 \\
\hline $\begin{array}{l}\geq 160 / 100 \mathrm{~mm} \\
\mathrm{Hg}\end{array}$ & 360 & 47 & 1.41 (0.88 to 2.26$)$ & 0.16 \\
\hline
\end{tabular}

CVDs, cardiovascular diseases.

to pathophysiological mechanisms, prognostic implications and therapeutic approaches. ${ }^{20-22}$ For example, the initiation of pharmacological therapy is recommended for adults with stage 2 hypertension. ${ }^{22}$ ACC/AHA Task Force on Clinical Practice Guidelines released the 2017 hypertension guideline, which defined SBP of 130-139 $\mathrm{mm} \mathrm{Hg}$ or DBP of $80-89 \mathrm{~mm} \mathrm{Hg}$ as stage 1 hypertension supported by the evidence from SPRINT. ${ }^{6}$ Based on the new criterion, the prevalence of hypertension would increase substantially in many countries. ${ }^{23-25}$ Although intensive blood pressure control was beneficial to cardiovascular events and total mortality, it was associated with an increased number of newly diagnosed patients with hypertension who may not develop CVD events in the future. ${ }^{23}$ In particular, with a large ageing population, there was a high prevalence of hypertension in China. ${ }^{26-28}$ It is estimated that 2.33 million cardiovascular deaths were attributable to increased blood pressure in China. ${ }^{14}$ Furthermore, contrary to western countries that 
CVD mortality has decreased significantly during the past years, CVD mortality has increased during the same period in China. ${ }^{35}$ Thus, whether the results of SPRINT apply to rural Chinese populations is a critical question to answer among Chinese populations.

In the current analysis by different blood pressure levels at baseline, the HR of CVDs mortality related to stage 1 hypertension defined by the 2017 ACC/AHA hypertension guideline (130-139/80-89 mm Hg) was not statistically higher than that related to SBP/DBP of $<120 /<80$ $\mathrm{mm} \mathrm{Hg}$. Previous studies have demonstrated diagnosed patients with hypertension tended to prescribe antihypertensive medications despite the lifestyle modifications management suggestions, ${ }^{1829}$ which may increase adverse effects caused by antihypertension treatment among the newly diagnosed patients such as acute kidney injury, acute renal failure, hypotension, syncope or electrolyte abnormality. ${ }^{13} 30$ In addition, the higher hypertension diagnosis costs due to treatment is another important issue. ${ }^{30}{ }^{31}$ Since there was a lack of awareness, adherence to hypertension guidelines as well as access to antihypertensive drugs in China, the health and cost-effectiveness of the new diagnostic criteria for hypertension should be evaluated further. The results in our study may help address the current evidence gaps about whether the 2017 ACC/AHA guideline could be applied to populations in rural China.

The 20-year prospective study included a relatively large sample size examining the association between high blood pressure and mortality from CVDs in rural China. The CVDs deaths in the current study were comparable with several previous studies in China. ${ }^{1332}$ A previous study suggested a north-south gradient in the mortality of CVDs due to the difference in the prevalence of hypertension in China. ${ }^{33}$ Furthermore, the Sino-Monitoring Trends and Determinants in Cardiovascular Disease (Sino-MONICA) study showed that the number of deaths caused by stroke was larger than that caused by coronary heart disease. ${ }^{34} \mathrm{In}$ addition, $73 \%$ of the stroke burden could be attributed to hypertension in China, and the prevalence of hypertension in stroke survivors in China was relatively high when compared with other countries. ${ }^{35}$ Besides, most of the stroke deaths $(64.3 \%)$ were attributable to ischaemic stroke in the current study. Previous studies indicate that atrial fibrillation is the most common cause of ischaemic stroke and an increased risk of stroke was observed in patients with hypertension with atrial fibrillation, ${ }^{36-39}$ which may be another reason for the larger number of stroke deaths compared with coronary heart disease. Further studies are needed to explore the role of atrial fibrillation in the association between hypertension and stroke mortality to confirm our findings. Fangshan District is located in the 'stroke belt' of China. ${ }^{40}$ Thus, the study is important to elucidate the association between stage 1 hypertension defined by the 2017 ACC/AHA hypertension guideline and cardiovascular deaths in rural China.

\section{Limitations of the study}

Nevertheless, the study has several limitations. First, we cannot exclude the influence of some potential confounding factors despite the fact that we conducted the analysis with careful adjustment. In particular, the definition of smoking, alcohol consumption, salt intake and the use of antihypertensive drugs was relatively simple due to limited information in the baseline questionnaire. Second, hypertension was defined by SBP/ DBP at baseline while we failed to acquire blood pressure measurements during follow-up, which may underestimate the strength of the associations we observed. Next, we had an insufficient sample size to explore whether the effects of hypertension on CVDs mortality differ by baseline comorbidities including diabetes or chronic kidney disease. In addition, information of death was obtained from the Death Surveillance System, the participants lost to follow-up were hard to detect and may cause potential bias. Therefore, further studies with a larger sample size are needed to validate the results in the study. More importantly, our study only included participants in rural China, which might limit the generalisability of the results to other populations with different socioeconomic status, environmental exposures or genetic background.

\section{CONCLUSION}

In conclusion, the current study revealed hypertension of $\geq 140 / 90 \mathrm{~mm} \mathrm{Hg}$ was an important risk factor of CVDs mortality, especially among people aged 35-59 years. However, stage 1 hypertension under the definition of 2017 ACC/AHA was not associated with an increased risk of CVDs mortality. This study indicated that adopting the new hypertension definition needs further consideration among rural Chinese populations.

Contributors MW, TW and Y-HH conceived and designed the paper. L-mL, WC, JL, YW, XQ, XT, QZ, SH, SZ, Y-HH, TW and DY coordinated the data acquisition and contributed to critical revision of the manuscript for important intellectual content. $M W, P G, W G$ and $C Y$ analysed the data. MW and TW drafted the manuscript. MW, TW, LL and Y-HH were responsible for the overall content of article and data analysis. The manuscript is approved by all authors for publication.

Funding This work was supported by the Key Project of Natural Science Funds of China (81230066) and National Natural Science Foundation of China (81473043, 81502874, 81573226, 81703291).

Competing interests None declared.

Patient consent for publication Not required.

Ethics approval The study was approved by the Institutional Review Board of Peking University Health Science Center.

Provenance and peer review Not commissioned; externally peer reviewed.

Data availability statement All data relevant to the study are included in the article or uploaded as supplementary information. All data relevant to the study are included in the article.

Open access This is an open access article distributed in accordance with the Creative Commons Attribution Non Commercial (CC BY-NC 4.0) license, which permits others to distribute, remix, adapt, build upon this work non-commercially, and license their derivative works on different terms, provided the original work is properly cited, appropriate credit is given, any changes made indicated, and the use is non-commercial. See: http://creativecommons.org/licenses/by-nc/4.0/. 


\section{ORCID iDs}

Mengying Wang http://orcid.org/0000-0003-0162-5355

Jun Lv http://orcid.org/0000-0001-7916-3870

Xun Tang http://orcid.org/0000-0002-6990-0168

Siyan Zhan http://orcid.org/0000-0001-7252-5349

\section{REFERENCES}

1 Forouzanfar $\mathrm{MH}$, Liu P, Roth GA, et al. Global burden of hypertension and systolic blood pressure of at least 110 to $115 \mathrm{~mm} \mathrm{Hg}, 1990$ 2015. JAMA 2017;317:165-82.

2 Mills KT, Bundy JD, Kelly TN, et al. Global disparities of hypertension prevalence and control: a systematic analysis of population-based studies from 90 countries. Circulation 2016;134:441-50.

3 Lewington S, Lacey B, Clarke R, et al. The burden of hypertension and associated risk for cardiovascular mortality in China. JAMA Intern Med 2016;176:524-32.

4 Blood Pressure Lowering Treatment Trialists' Collaboration. Blood pressure-lowering treatment based on cardiovascular risk: a metaanalysis of individual patient data. Lancet 2014;384:591-8.

5 Angell SY, De Cock KM, Frieden TR. A public health approach to global management of hypertension. Lancet 2015;385:825-7.

6 Whelton PK, Carey RM, Aronow WS, et al. 2017 ACC/AHA/AAPA ABC/ACPM/AGS/APhA/ASH/ASPC/NMA/PCNA guideline for the prevention, detection, evaluation, and management of high blood pressure in adults: a report of the American College of Cardiology/ American heart association Task force on clinical practice guidelines. J Am Coll Cardiol 2018:71:e127-248.

7 Williams B, Mancia G, Spiering W, et al. 2018 ESC/ESH guidelines for the management of arterial hypertension. Eur Heart $J$ 2018;39:3021-104.

8 Wright JT, Williamson JD, Whelton PK, et al. A randomized trial of intensive versus standard blood-pressure control. N Engl J Med 2015;373:2103-16.

9 Bundy JD, Li C, Stuchlik P, et al. Systolic blood pressure reduction and risk of cardiovascular disease and mortality: a systematic review and network meta-analysis. JAMA Cardiol 2017;2:775-81.

10 Kulenthiran S, Ewen S, Böhm M, et al. Hypertension up to date: SPRINT to SPYRAL. Clin Res Cardiol 2017;106:475-84.

11 Sun X, Guo Y, Nie Z, et al. Influence of baseline systolic blood pressure on the relationship between intensive blood pressure control and cardiovascular outcomes in the systolic blood pressure intervention trial (sprint). Clin Res Cardiol 2019;108:273-81.

12 Qureshi Al, Palesch YY, Barsan WG, et al. Intensive blood-pressure lowering in patients with acute cerebral hemorrhage. $N$ Engl J Med 2016;375:1033-43.

13 Qi Y, Han X, Zhao D, et al. Long-term cardiovascular risk associated with stage 1 hypertension defined by the 2017 ACC/AHA hypertension guideline. J Am Coll Cardiol 2018;72:1201-10.

$14 \mathrm{He}$ J, Gu D, Chen J, et al. Premature deaths attributable to blood pressure in China: a prospective cohort study. Lancet 2009;374:1765-72.

15 Zhou M, Wang H, Zhu J, et al. Cause-specific mortality for 240 causes in China during 1990-2013: a systematic subnational analysis for the global burden of disease study 2013. Lancet 2016;387:251-72.

16 Bundy JD, He J. Hypertension and related cardiovascular disease burden in China. Ann Glob Health 2016;82:227-33.

17 Allen N, Berry JD, Ning H, et al. Impact of blood pressure and blood pressure change during middle age on the remaining lifetime risk for cardiovascular disease: the cardiovascular lifetime risk pooling project. Circulation 2012;125:37-44.

18 Wang S, Wu H, Zhang Q, et al. Impact of baseline prehypertension on cardiovascular events and all-cause mortality in the general population: a meta-analysis of prospective cohort studies. Int $\mathrm{J}$ Cardiol 2013;168:4857-60.

19 Buck C, Baker P, Bass M, et al. The prognosis of hypertension according to age at onset. Hypertension 1987;9:204-8.
20 Rapsomaniki E, Timmis A, George J, et al. Blood pressure and incidence of twelve cardiovascular diseases: lifetime risks, healthy life-years lost, and age-specific associations in 1.25 million people. Lancet 2014;383:1899-911.

21 Keith NM, Wagener HP, Barker NW. Some different types of essential hypertension: their course and prognosis. Am J Med Sci 1974;268:336-45.

22 Whelton PK, Carey RM, Aronow WS, et al. 2017 ACC/AHA/AAPA/ ABC/ACPM/AGS/APhA/ASH/ASPC/NMA/PCNA guideline for the prevention, detection, evaluation, and management of high blood pressure in adults: Executive summary: a report of the American College of Cardiology/American heart association Task force on clinical practice guidelines. Hypertension 2018;71:1269-324.

23 Bundy JD, Mills KT, Chen J, et al. Estimating the association of the 2017 and 2014 hypertension guidelines with cardiovascular events and deaths in US adults: an analysis of national data. JAMA Cardiol 2018;3:572-81.

24 Dorans KS, Mills KT, Liu Y, et al. Trends in prevalence and control of hypertension according to the 2017 American College of Cardiology/ American heart association (ACC/AHA) guideline. J Am Heart Assoc 2018;7:e008888.

25 Kibria GMA, Swasey K, Choudhury A, et al. The new 2017 ACC/AHA guideline for classification of hypertension: changes in prevalence of hypertension among adults in Bangladesh. J Hum Hypertens 2018;32:608-16.

26 National Bureau of Statistics of the People's Republic of China. The sixth national population census of the People's Republic of China, 2010. Available: http://www.stats.gov.cn/tjsj/pcsj/rkpc/6rp/in [Accessed 5 Dec 2018].

27 Lu J, Lu Y, Wang X, et al. Prevalence, awareness, treatment, and control of hypertension in China: data from 1.7 million adults in a population-based screening study (China peace million persons project). Lancet 2017;390:2549-58.

28 Wang Z, Chen Z, Zhang L, et al. Status of hypertension in China: results from the China hypertension survey, 2012-2015. Circulation 2018;137:2344-56.

29 Wang J-G, Liu L. Global impact of 2017 American College of Cardiology/American heart association hypertension guidelines: a perspective from China. Circulation 2018;137:546-8.

30 Bakris G, Sorrentino M. Redefining hypertension - assessing the new blood-pressure guidelines. N Engl J Med 2018;378:497-9.

31 Gijón-Conde T, Sánchez-Martínez M, Graciani A, et al. Impact of the European and American guidelines on hypertension prevalence, treatment, and cardiometabolic goals. J Hypertens 2019;37:1393-400.

32 Zhu N, Yu C, Guo Y, et al. Adherence to a healthy lifestyle and all-cause and cause-specific mortality in Chinese adults: a 10-year prospective study of 0.5 million people. Int J Behav Nutr Phys Act 2019;16:98.

33 Zhao D, Liu J, Wang W, et al. Epidemiological transition of stroke in China: twenty-one-year observational study from the Sino-MONICABeijing project. Stroke 2008;39:1668-74

34 Wu Z, Yao C, Zhao D, et al. Sino-MONICA project: a collaborative study on trends and determinants in cardiovascular diseases in China, part I: morbidity and mortality monitoring. Circulation 2001;103:462-8.

35 Wang W, Jiang B, Sun $\mathrm{H}$, et al. Prevalence, Incidence, and Mortality of Stroke in China: Results from a Nationwide Population-Based Survey of 480687 Adults. Circulation 2017;135:759-71.

36 Brandes A, Smit MD, Nguyen BO, et al. Risk factor management in atrial fibrillation. Arrhythm Electrophysiol Rev 2018;7:118-27.

37 Gage BF, Waterman AD, Shannon W, et al. Validation of clinical classification schemes for predicting stroke: results from the National Registry of atrial fibrillation. JAMA 2001;285:2864-70.

38 Tohgi $\mathrm{H}$, Tajima T, Konno T, et al. The risk of cerebral infarction in non-valvular atrial fibrillation: effects of age, hypertension and antihypertensive treatment. Eur Neurol 1991;31:126-30.

39 Wolf PA, Abbott RD, Kannel WB. Atrial fibrillation as an independent risk factor for stroke: the Framingham study. Stroke 1991;22:983-8.

40 Tang X, Hu Y, Chen D, et al. The Fangshan/Family-based ischemic stroke study in China (FISSIC) protocol. BMC Med Genet 2007;8:60. 